\title{
Investigating the relationships between environmental stressors and stream condition using Bayesian belief networks
}

\author{
J. DAVID ALLAN*, LESTER L. YUAN ${ }^{\dagger}$, PAUL BLACK ${ }^{\ddagger}$, TOM STOCKTON $^{\ddagger}$, PETER E. DAVIES ${ }^{\S}$, \\ REGINA H. MAGIEROWSKI ${ }^{\S}$ AND STEVE M. READ \\ *School of Natural Resources E Environment, University of Michigan, Ann Arbor, MI, U.S.A. \\ ${ }^{\dagger}$ US Environmental Protection Agency, Office of Research and Development, National Center for Environmental Assessment, Washington, \\ DC, U.S.A. \\ ${ }^{\ddagger}$ Neptune and Company, Inc., Lakewood, CO, U.S.A. \\ ${ }^{\S}$ School of Zoology, University of Tasmania, Hobart, Tas., Australia \\ 'Forestry Tasmania, Hobart, Tas., Australia
}

\section{SUMMARY}

1. Stream reaches found to be impaired by physical, chemical or biological assessment generally are associated with greater extent of urban and agricultural land uses, and lesser amount of undeveloped lands. However, because stream condition commonly is influenced by multiple stressors as well as underlying natural gradients, it can be difficult to establish mechanistic relationships between altered land use and impaired stream condition.

2. This study explores the use of Bayesian belief networks (BBNs) to model presumed causal relationships between stressors and response variables. A BBN depicts the chain of causal relationships resulting in some outcome such as environmental impairment and can make use of evidence from expert judgment as well as observational and experimental data.

3. Three case studies illustrate the flexibility of BBN models. Expert elicitation in a workshop setting was employed to model the effects of sedimentation on benthic invertebrates. A second example used empirical data to explore the influence of natural and anthropogenic gradients on stream habitat in a highly agricultural watershed. The third application drew on several forms of evidence to develop a decision support tool linking grazing and forestry practices to stream reach condition.

4. Although data limitations challenge model development and our ability to narrow the range of possible outcomes, model formulation forces participants to conceptualise causal mechanisms and consider how to resolve data shortfalls. With sufficient effort and resources, models with greater evidentiary strength from observational and experimental data may become practical tools to guide management decisions.

5. Such models may be used to explore possible outcomes associated with a range of scenarios, thus benefiting management decision-making, and to improve insight into likely causal relationships.

Keywords: Bayesian belief network, causal inference, multiple stressors, stream impairment, stream management

\section{Introduction}

Significant advances in the assessment of impaired waterways over the past several decades have resulted in extensive government-sponsored programmes to evaluate river condition at regional and national scales. With the advent of large-scale monitoring, individual stream reaches can be categorised on a continuum of poor to

Correspondence: J. David Allan, School of Natural Resources \& Environment, University of Michigan, Ann Arbor, MI 48109, U.S.A.

E-mail: dallan@umich.edu 
excellent condition, and whole regions can be compared with regard to average level of impairment (e.g. Paulsen et al., 2008; Davies et al., 2010). This information is crucial to determining if regulatory standards are met, and identifying locations where active management is needed to counteract stressors and improve stream condition.

Diagnosis of cause of impairment obviously must accompany assessment if restorative actions are to be well focused. Although considerably less literature formally addresses this issue, relative to the very substantial literature on biological assessment, the need for diagnosis has not gone unrecognized. U.S. EPA maintains an online Causal Analysis/Diagnosis Decision Identification System intended to assist in the identification of stressors responsible for impaired waters. There may be sufficient information available on chemical and physical conditions to strongly suggest cause of impairment, and indeed, the cause may be obvious when there is a recognisable contaminant source in an otherwise apparently pristine landscape. Biological assessment data also can be mined for further insights, as when the traits or tolerances of particular species can be strongly associated with particular stressors (Yuan, 2004; Pollard \& Yuan, 2010).

Often, however, identifying the cause of impairment is challenging (Downes, 2010). Although many studies now demonstrate that indicators of altered and disturbed landscape are effective predictors of impaired stream conditions, mechanisms of impairment may be difficult to determine because of covariation between anthropogenic influences and natural landscape gradients; the potential for multiple, scale-dependent mechanisms; nonlinearities; and possible legacy effects (Allan, 2004). A recurring theme in reviews of the influence of land use upon river habitats and biota by Allan (2004), Hughes, Wang \& Seelbach (2006), Johnson \& Host (2010) and Steel et al. (2010) has been the need for an improved understanding of mechanistic relationships.

Bayesian belief networks (BBNs) offer a useful framework to depict the chain of causal relationships resulting in environmental impairment, and for quantifying the relative influence of individual linkages with explicit uncertainty (Borsuk, Stow \& Reckhow, 2004). BBNs combine an influence diagram that can be used to provide a visual representation of the assumed cause and effect relationships for the problem at hand, and a parent-daughter state probability structure that quantifies pathway of influence. Bayesian networks hold promise for predictions of responses to multiple drivers, to identify key drivers, and to guide management practices in real-world situations through simulation and scenario modelling.

Visually, a Bayesian belief network (BBN) is an influence diagram depicting logical or causal relations among factors that influence the likelihood of outcome states of some parameter of interest, such as ecological condition or species viability. Variables are represented as nodes, with arrows depicting the direction of causation or association (Jensen, 1996). Causation is considered to flow from a 'parent' node to a 'child' node and is unidirectional (Fig. 1). The value of the variable represented by each node is

Fig. 1 A simple influence diagram for a stream macroinvertebrate community.

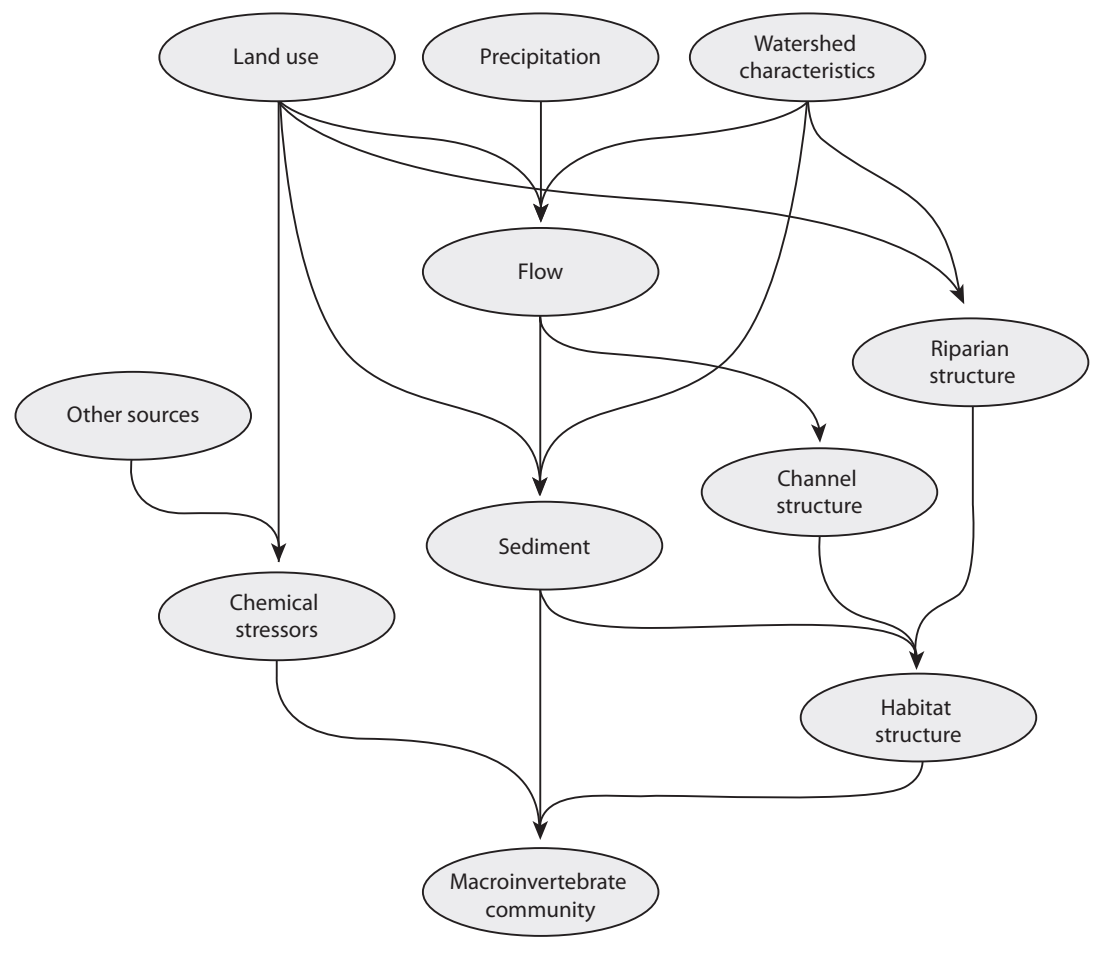

(C) 2011 Blackwell Publishing Ltd, Freshwater Biology, 57 (Suppl. 1), 58-73 
expressed as a probability distribution, conditioned on the values of parent nodes. In Fig. 1, the probability that stream flow will be a particular value is influenced by land use, precipitation and terrain. Once the model structure has been defined, the effects of parent nodes on child nodes are quantified from expert knowledge, statistical analysis of existing data or other types of associations and evidence (Korb \& Nicholson, 2004; Pollino et al., 2007). For example, the probability distribution for precipitation may be determined by an analysis of the past 20 years of summer rainfall. Specification of the parameterized $B B N$ is an iterative process, allowing model structure to be modified as it is developed.

Development of a BBN typically begins with the selection of a problem of interest and a related conceptual model of relationships between key drivers and responses at appropriate scales. Appropriate output variables are selected, such as water quality or some biological indicator, followed by specification of initial model structure, which is an unparameterised causal network, from knowledge or data.

Interest in the use of BBNs for ecological modelling has grown in recent years to include applications to a variety of problems including fisheries assessment (Lee \& Rieman, 1997; Kuikka et al., 1999), forest regeneration (Haas, Mowrer \& Shepperd, 1994), habitat restoration (Rieman et al., 2001) and emerging infectious diseases (Plowright et al., 2008). Applications to aquatic ecosystems include eutrophication in the Neuse River estuary, North Carolina (Borsuk et al.,2004), an ecological assessment of the impacts of changed environmental conditions on native fish communities in a catchment in Victoria, Australia (Pollino et al., 2007) and to assist in prioritizing river restoration options in response to changing flows and land use (Stewart-Koster et al., 2005; Webb, Stewardson \& Koster, 2010).

Although the use of BBNs to represent ecological knowledge and uncertainty clearly is growing, their use is still rare. The purpose of this study is to explore some potential advantages and disadvantages of using BBNs to improve understanding of causes of stream impairment in order to support management decisions. We illustrate their utility with three case studies: one developed using knowledge elicitation to quantify a specific stressorresponse relationship, a second constructed with data from a specific study area and a mixed model constructed with a range of evidentiary sources and inferential strength.

\section{Influence of sediments on low-gradient streams - an expert elicitation example}

Sedimentation was reported to be the second most common cause of pollution in assessed rivers and streams by the 1998 National Water Quality Inventory (U.S. Environmental Protection Agency, 2000), affecting 31\% of those considered impaired. This case study was undertaken to determine whether the information necessary to specify a BBN describing the effect of sedimentation on macroinvertebrate populations could be elicited from a group of stream ecologists with relevant experience, in collaboration with specialists in Bayesian modelling. To quantify this stressor-response relationship based on expert judgment, a stream setting (a Midwestern, lowgradient stream) and a type of impairment (introduction of excess fine sediment) were specified along with the relevant chemical, physical and biological aspects of the ecosystem. The scale of influence was considered to be a single riffle in two identical catchments, both originally forested but with different disturbance histories of logging and conversion to row crop agriculture, causing sediment loads to vary across the catchments. The ecologists then described how these factors were connected, and were asked to predict quantitatively how different attributes of the macroinvertebrate assemblage would change in response to increased levels of fine sediment, compared with the baseline condition.

The elicitation approach consisted of several steps, including conditioning, model structuring and elicitation of probabilistic relationships among variables. Conditioning, which refers to the development of a common problem focus among domain experts, sharing of relevant knowledge and introduction to Bayesian approaches, occurred prior to meeting as a group, by email and a conference call. This also facilitated initial model structuring, which involved establishing assumptions and conditions for the model as well as relationships between variables. Several initial influence diagrams were discussed and revised, resulting in a preliminary influence diagram of possible relationships between sediment loading, sediment effects and macroinvertebrate populations of potential interest (Fig. 2).

A two-day workshop allowed Bayesian modellers to lead the stream ecologists through the remaining elicitation steps, starting with a discussion of the preliminary influence diagram. These discussions resulted in several changes to Fig. 2 including (i) splitting primary producers (benthic algae) into over-story and under-story components, expected to respond differently to changes in sediment loading; (ii) adding a bed-mobility component, which can affect macrobenthic organism life-history traits (e.g. shorter- versus longer-lived taxa); (iii) consideration of organic and inorganic components of sediments; and (iv) refining the filterers node to separate those that respond positively to organic inputs (food particles) from 


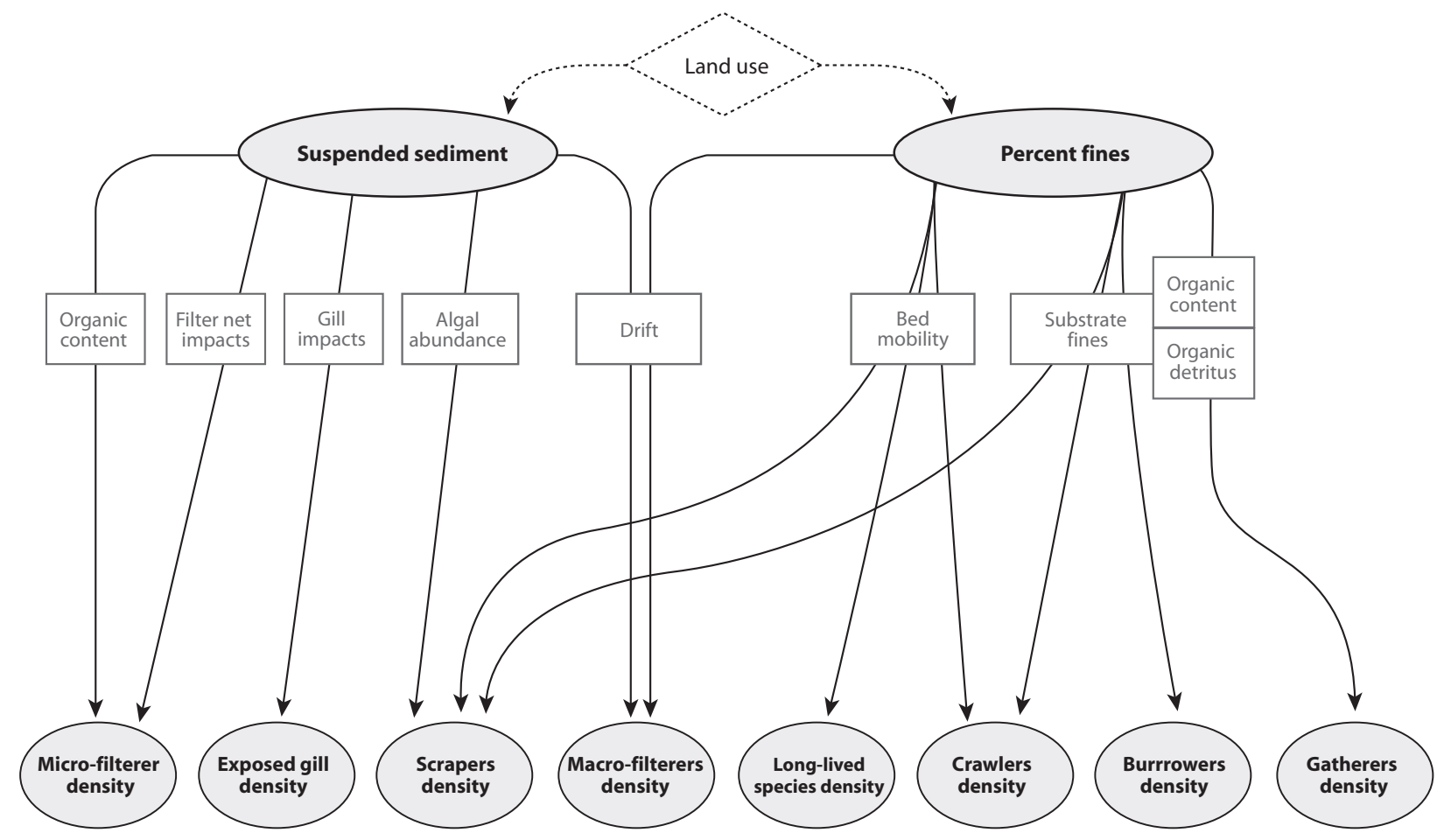

Fig. 2 The preliminary influence diagram developed for the expert elicitation modelling of the effects of sediments on macroinvertebrates.

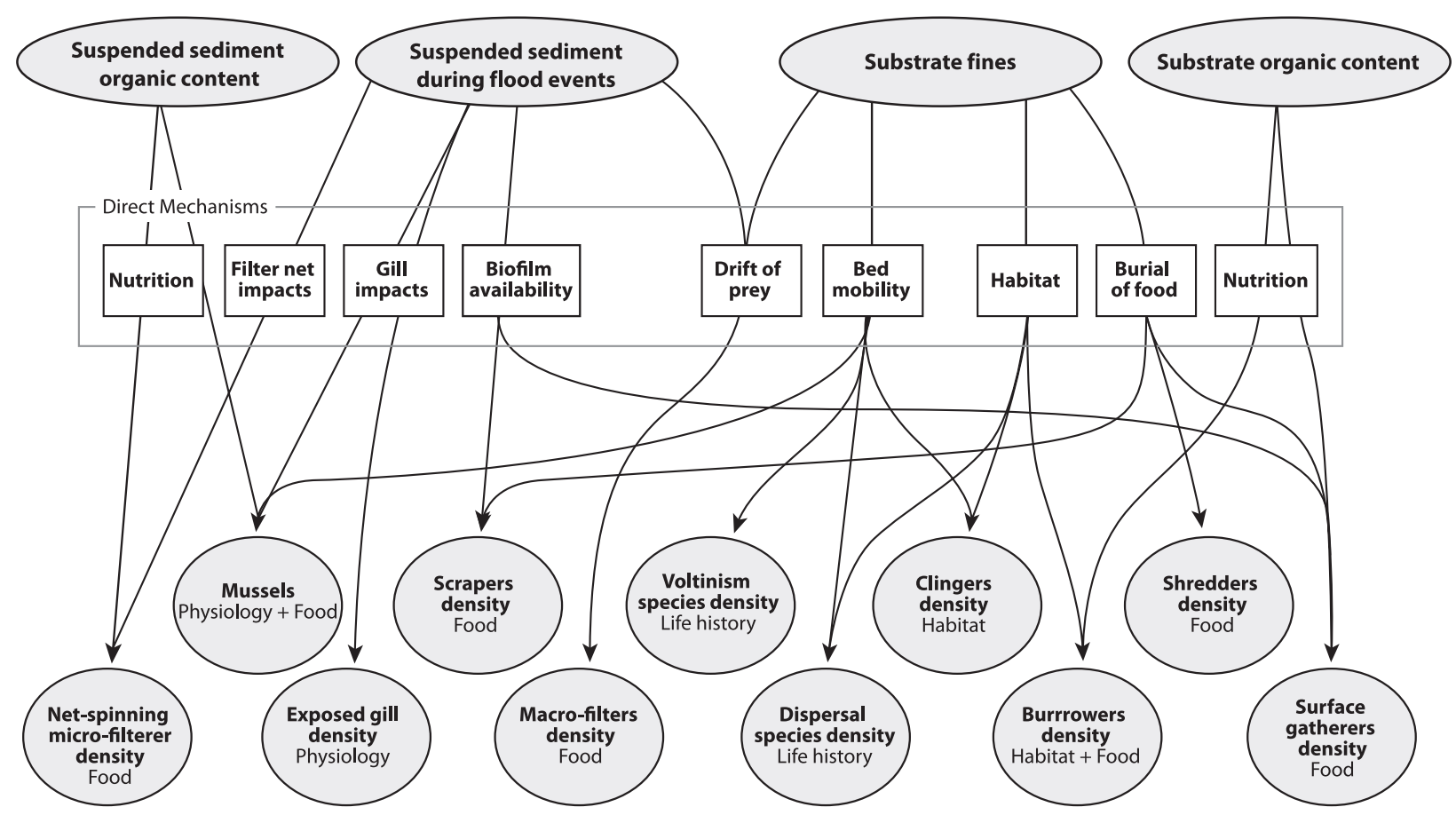

Fig. 3 The final influence diagram of the effects of sediments on macroinvertebrates.

those that might respond adversely to an increase in particles (net damage, abrasion, etc.). This resulted in a final influence diagram, which then was used for a subsequent round of more formal model structuring. The final model (Fig. 3) had three levels, in which the top level represented sediment conditions, which were the 
presumed agent causing biological responses; and the bottom level nodes represented macroinvertebrates grouped by their functional roles and life histories. The middle level represented mechanisms by which sediment loading would affect each macroinvertebrate group. This level was not modelled explicitly, but used to guide discussions and elicitation regarding the relationship between sediment changes and invertebrate responses.

Probability distributions describing the relationship between changes in each sediment condition and the response of each macroinvertebrate node were then elicited. Each functional group of macroinvertebrates was modelled separately, assuming no interactive effects between them. In practice, the elicitation approach focused on quantile elicitation for given levels of sedimentation, with a graphical interface that portrayed the type of functional form that was implied by the elicited input. As an example, clingers were assumed to respond negatively to embeddedness because of their need for exposed pebbles and cobbles, and to not benefit from organic content of sediments. The distribution of possible percentage declines in clinger density was considered at each of six levels of embeddedness chosen by the stream ecologists (20,30, 40,60, 80 and 100\%). At each level of embeddedness, the experts were first asked to specify reasonable maximum and minimum percentage declines in clinger density. Then, experts were asked to specify a percentage of clinger decline at which the range of values above and below this percentage were equally likely. Starting with the median, successive halving of the quantiles was performed until the stream ecologists were comfortable that the shape of the distribution was adequately characterised.

A graphical depiction of the probability distribution of per cent decline in clinger density in response to increasing sedimentation (Fig. 4) was then used to provide immediate feedback and allow adjustment as necessary. Each point in Fig. 4 represents the response of the group of experts for the quantile response to a given embeddedness. A connected line in Fig. 4 represents the response of the group of experts for a set of specific quantiles. Quantiles depicted on this plot are the reasonable minimum and maximum, the median and both quartiles.

For example, the ecologists agreed that $20 \%$ sedimentation would cause little decline in clingers, whereas at $40 \%$ fines, per cent decreases in clinger density were expected to be substantial and range from 10 to $70 \%$. This graph suggests a threshold effect for sedimentation levels existed between 30 and $40 \%$ embeddedness. At lower levels of substratum fines, the populations of clingers would not be strongly affected, but above this threshold, a

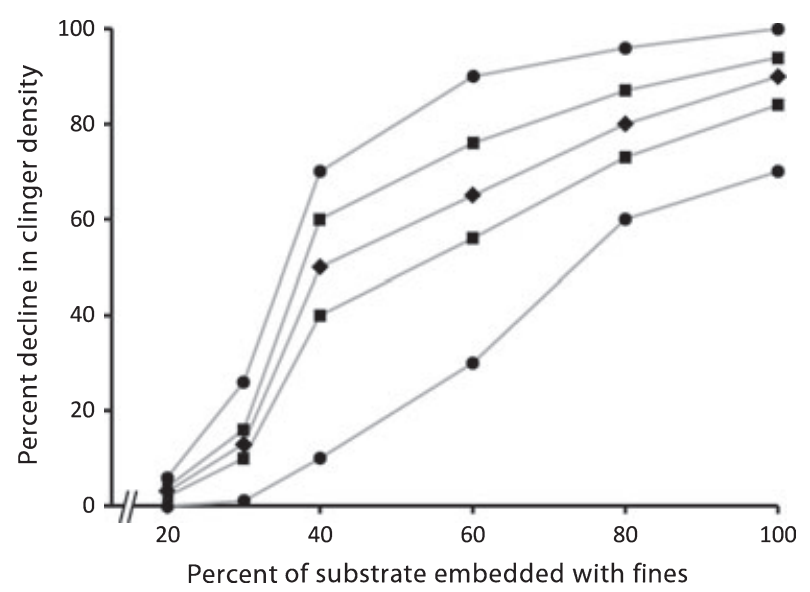

Fig. 4 Graphical depiction of elicited input for the clinger functional group. Quantiles of the underlying distribution of per cent decline in clinger density were elicited based on a specified level of sedimentation measured as per cent of substratum embedded with fines. For example, the median per cent decline in population of clingers at $40 \%$ embeddedness was elicited as $50 \%$, with reasonable minimum and maximum per cent decline respectively of about 10 and $70 \%$. $\boldsymbol{\Delta}=$ median, $\boldsymbol{\square}=25$ th and 75 th quantiles, $\boldsymbol{0}=$ minimum and maximum expected response.

much more substantial drop in populations is expected. Even at $100 \%$ embeddedness, the stream ecologists expected that a reasonable probability existed for some clingers to survive, based on their assumption that some substratum would be available.

Subsequent elicitations for shredders and burrowers adopted the same general relationship and focused on likely differences in the responses of the different functional groups. Shredders were expected to be less sensitive to sedimentation than clingers, and burrowers were expected to be influenced equally or to a greater extent by the organic content of the sediments. This expanded the elicitation to include categorisation of organic matter content $(<1 \%, 1-5 \%,>5 \%)$. Finally, the elicited distributions were fit to a nonlinear regression model that can be used to predict responses at other levels of embeddedness.

It would be difficult to directly test the outcome of this elicitation, because data corresponding closely to the scenario used are not readily available. However, the outcome of this elicitation exercise is broadly consistent with the widespread reporting of sediments as a leading cause of stream impairment (USEPA 2000) and their generally adverse effect on stream biota (Allan \& Castillo, 2007). A recent analysis using three large data sets from different regions of the U.S. provided clear evidence that clinger relative abundance declines as sediment levels increase, and this relationship was consistent across geographical location (Pollard \& Yuan, 2010). More 
explicit tests would examine the appropriateness of the $\sim 40 \%$ embeddedness threshold, whether shredders indeed respond at a higher threshold, and the influence of organic matter content on the response of burrowers.

\section{Southeastern Michigan catchments - modelling from data}

The Huron and Raisin catchments of southeastern Michigan comprise varied landscapes and a wide range of stream condition. Both originate in a terrain of rolling hills, lakes, wetlands and second-growth forest underlain by glacial outwash and till, and both transition into regions of low relief underlain by lacustrine silts and clays. The Huron has more urban development (28 versus $12 \%$ for the Raisin), and the Raisin supports much more agricultural activity (63 versus 25\% for the Huron). Because of its greater extent of agriculture, the lower Raisin also has undergone more hydrological modification, including channelization and use of field drainage tiles. Field studies of these two catchments document that indicators of good habitat and biological status correlate negatively with increasing agricultural and urban land associated with sampling locations. Variation in land use and natural features within the sub-catchments upstream of sampled stream reaches typically explains from onethird to two-thirds of the observed variation among stream sites in various metrics (Roth, Allan \& Erickson, 1996; Lammert \& Allan, 1999; Diana, Allan \& Infante, 2006; Infante et al., 2008; Infante \& Allan, 2010).

Because a strong natural gradient separated upper catchment areas of glacial geology from lower regions of low-relief lakebed sediments, field studies took place solely in the upper regions of both catchments to minimise the influence of natural variation and focus primarily on human influence. However, as is often the case, natural and anthropogenic gradients within these catchments co-varied, because developed landscapes typically were those most suitable for agricultural or urban use. In addition, land use at riparian and catchment scales tended to correlate, making it difficult to argue for stronger causality to one or the other scale based on statistical relationships. These results from the Raisin and Huron studies are typical of many studies of their kind (Steel et al., 2010).

Although natural and anthropogenic gradients proved difficult to separate, there were consistent patterns of association of the biota with the landscape. This is clearly seen in the analysis by Infante et al. (2008), who used clustering algorithms to search for similar biological assemblages, and then asked whether each biological assemblage could be associated with distinct landscape features. Indeed, the biological assemblage with the characteristics of a diverse and healthy assemblage (highest diversity of species and functional attributes, fewest tolerant species) occurred at sites associated with the greatest amount of undisturbed (forest plus wetland) land and coarse geology. Conversely, the biological assemblage characterised by low diversity and tolerant species occurred at sites with greatest agriculture and fine geology. Coarse geology includes coarse end and ground moraines, ice contact and outwash, and more readily allows water infiltration; fine geology includes fine end and ground moraines and clay and sand lakeplain, which have lower infiltration rates (Farrand \& Bell, 1982).

Collectively, these studies indicate consistent relationships of stream condition with landscape characteristics; in addition, the confounding of natural and anthropogenic gradients remains, for this study system, also a consistent finding.

These results motivated the second case study, to develop a BBN using data from the study catchments in an attempt to specify how multiple components of stream habitat responded to natural and anthropogenic gradients. More specifically, the goal was to construct a model that would predict best attainable conditions for the study catchments in terms of overall habitat quality and biological condition. This modelling exercise used available data from 47 sites to explore whether measures of natural and anthropogenic gradients across sub-catchments could be used to model habitat condition, which was then expected to serve as a proxy for biological condition of stream sites.

Statistical analysis indicated that stream condition was positively associated with the extent of undisturbed land (forest + wetland), with coarse glacial geology, and with higher stream slope. Because land use at the subcatchment spatial scale and within 100-m wide stream buffers were correlated, it was difficult to determine empirically which scale was preferable for modelling purposes. However, because of the importance generally attributed to riparian buffers in protecting stream condition, and the practicality of management prescriptions for protected buffer strips, forested riparian was selected as one node representing prior conditions. Catchment geology may reasonably be presumed to represent hydrological flowpaths and indirectly represent topography (fine sediments are associated with low gradient sites). Because geology is mapped at too coarse a spatial scale ( $1: 500000)$ to meaningfully distinguish between riparian and sub-catchment conditions, and also because the entire sub-catchment plausibly affects stream hydrology, this variable was quantified at the sub-catchment scale. 
64 J. David Allan et al.

Finally, the slope of a 2-km stream reach centred on the study site determined using ArcGIS was selected as an additional prior node. Thus, stream habitat condition was assumed to be influenced by three prior conditions: subcatchment coarse geology and reach slope, both measures of any natural gradient in stream condition and extent of undisturbed land in the riparian, considered a measure of (the absence of) human disturbance. The model focused on the prediction of habitat condition, given the state of the three nodes selected to represent natural and anthropogenic variation across sub-catchments.

Habitat condition was defined as the sum of channel, flow, substratum and bank condition. These in turn were determined from the state of seven intermediate nodes, including the presence of gravel and riffles as determinants of channel condition, and five metrics from a standardised habitat survey (MDEQ, 1997) similar to habitat survey protocols found in Barbour et al. (1999). Figure 5 depicts an influence diagram that was developed from correlation matrices that included large number of variables, and from earlier results (Diana et al., 2006; Infante et al., 2008). In addition, a cluster analysis of fish assemblages resulted in site groupings that could be easily characterised as 'good', 'agricultural' and 'urban' sites based on their land use, and these also were associated with easily interpreted suites of habitat features.

Development of a BBN model for Fig. 5 proceeded by converting each node into two or more discrete states (e.g. low, medium and high slopes; low, medium and high gravel), with an actual data range associated with each state of each node. Each arrow in Fig. 5 represents a conditional probability table (CPT) that gives the likeli- hood that, e.g. a site with low slopes will have low, medium or high occurrence of gravel. In general, we did not look for three equal sub-divisions of the data range, since that might imply that one-third of the data fall in the 'poor' range and one-third in the 'best' range. All nodes were divided into three states based on frequency distribution plots of each variable and inspection for breaks in the data, and all CPT's were then determined empirically by the fraction of observations that occupied each cell of a $3 \times 3$ matrix. Figure 6 provides an example, and also illustrates how the approach quantifies uncertainty. In essence, sites with low slopes are unlikely to have very much gravel, whereas sites with high slopes are likely to have a good amount. However, for sites of intermediate slope, it is not possible to predict the amount of gravel.

Figure 7 shows the final model, with prior nodes set to what are considered the least favourable (left panel) and most favourable (right panel) conditions. The probability of finding excellent habitat is roughly twice as high when the riparian buffer is undisturbed; the sub-catchment consists of coarse geology, and the stream slope is high.

A true test of this model would require an independent data set for a similar ensemble of sites and landscapes. However, a kind of internal validation was conducted by examining the fish assemblages found at individual sites predicted to have excellent habitat. An earlier study (Infante et al., 2008) clustered sites on the basis of their fish assemblages, and identified one cluster of sites as 'best' based on their diversity of fish species and also diversity of functional traits (feeding roles, spawning needs, habitat preferences, characterisation as intolerant of pollution). Habitat quality predicted from a BBN requiring only

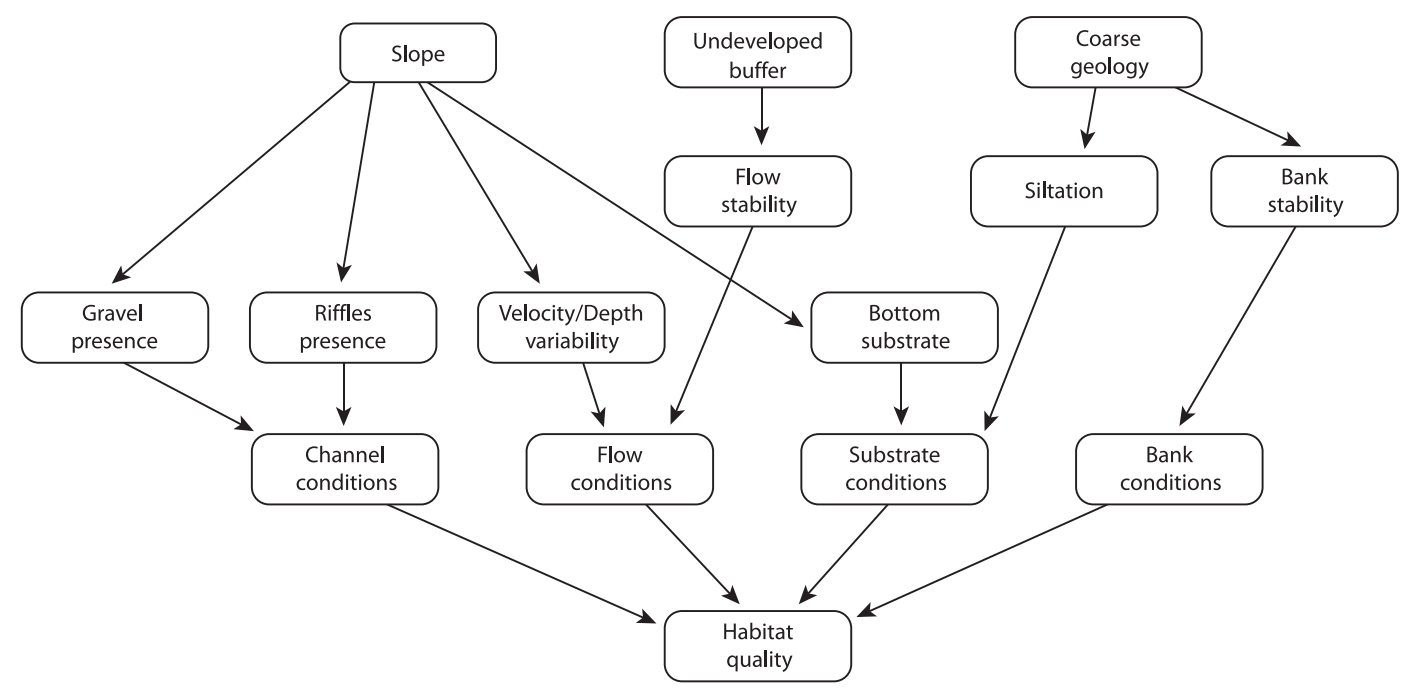

Fig. 5 The Bayesian belief network developed to represent the natural and anthropogenic drivers likely to promote desirable habitat and biological conditions in a Midwestern agricultural landscape, based on data from a number of studies of the Huron and Raisin Rivers in southeastern Michigan. 


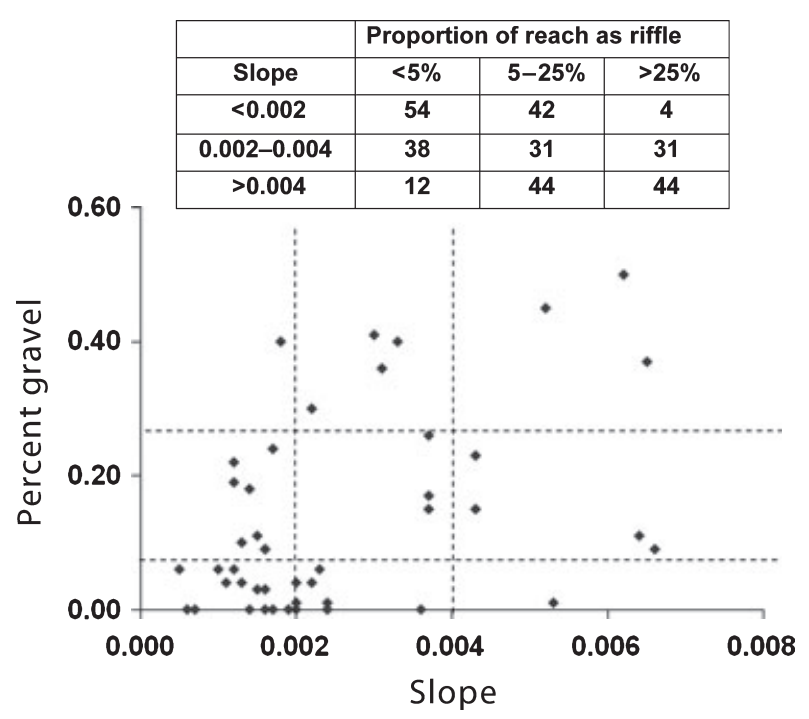

Fig. 6 Scatter plot showing the tendency for reaches of greater slope to have more gravel present. Slope and occurrence of gravel were each divided into three states (low, medium and high) using natural breaks, and the association of observations was used to estimate conditional probabilities. As the embedded table illustrates, sites with low slope are unlikely to have a lot of gravel, and vice-versa; for sites of intermediate slope, the probability of gravel occurring is too uncertain to predict.

catchment geology, buffer land use and slope as inputs was in good accord with expectations of encountering the 'best' fish group (Table 1).

\section{Tasmanian grazing and forestry land-use management - a mixed evidence model}

A decision support tool was required to inform management strategies focused on the influence of two dominant land uses - extensive grazing and hardwood forestry and riparian management on the ecological condition of rivers in Tasmania, Australia. This motivated the development of a conceptual model that linked catchment land use, catchment and reach scale riparian vegetation condition and a variety of regional landscape contexts to intermediate responses in hydrology, sediment and nutrient regimes, and in turn to changes in stream benthic macroinvertebrates and algae. A range of evidence was obtained to structure and parameterize these relationships in a BBN, with an emphasis on gathering local, regionally relevant data and evidence. Much of this evidence was gathered specifically for the development of the BBN, and while yet to be published in the peer-reviewed literature, was subject to critical review by the experts involved in elicitation during BBN development.

Table 2 illustrates the types of evidence and their relative inferential strength. These included expert elici- tation, targeted data mining, two 'gradient' studies designed stream surveys in catchments across a range of area under grazing and forest land uses, field-derived measures of instream processes and stream mesocosm experiments. During BBN development, we rated and documented the inferential strength of each piece of evidence, as well as the evidentiary basis for each set of parent-child relationships. Expert elicitation involved local stream ecologists and agricultural scientists with intensive knowledge of the problem area and geographical setting. Elicitation was used in the development of the primary conceptual model as the basis for BBN development (i.e. informing the BBN structure), identifying important contexts and modifiers (e.g. geomorphology, dominant soil types and hydrological regions) of ecological responses as BBN input nodes and evaluating possible states and CPT entries for nodes for which direct evidence and/or local knowledge was poor or absent. Our elicitation process was also supported by the use of data from local research into land-use impacts on stream biota (e.g. Davies \& Nelson, 1994; Davies et al., 2005a,b; Smith, Davies \& Munks, 2009), and a substantial effort to characterise the geomorphological character and behaviour of Tasmanian river systems (Jerie, Houshold \& Peters, 2001, 2003).

Data mining was used to refine the final conceptual model (Fig. 8) and related BBN. Data mining was initiated by collation of an extensive data set of benthic macroinvertebrate assemblages identified to family level, benthic algal cover and site-level habitat data (from 166 sites with 781 sampling events between 1999 and 2006) from northern and eastern Tasmanian rivers (DPIW, unpubl. data). Other spatial data compiled for development of an aquatic conservation framework (CFEV, http:/ / www.dpiw. tas.gov.au/inter-nsf/ThemeNodes/CGRM-7JH6CM?open, DPIW 2008) were also used to identify catchment and stream drainage and study reach characteristics - including slope, local geomorphology, elevation and riparian vegetation condition at reach and catchment scales. Additional data sets on land use (e.g. ANDRL, 2008) and hydrological regionalisation (Hughes, 1987) were also combined with these data using ArcGIS to attribute stream links and catchments.

Multivariate and correlation analysis showed that several metrics of macroinvertebrate community structure, the number and proportion of mayfly, stonefly and caddisfly (\%EPT) families and the ratio of observed to expected families $(\mathrm{O} / \mathrm{E})$ derived using the AUSRIVAS sampling protocol (Australian River Assessment Scheme, Davies, 2000), were strongly correlated with catchment land-use variables. The strongest relationships were neg- 

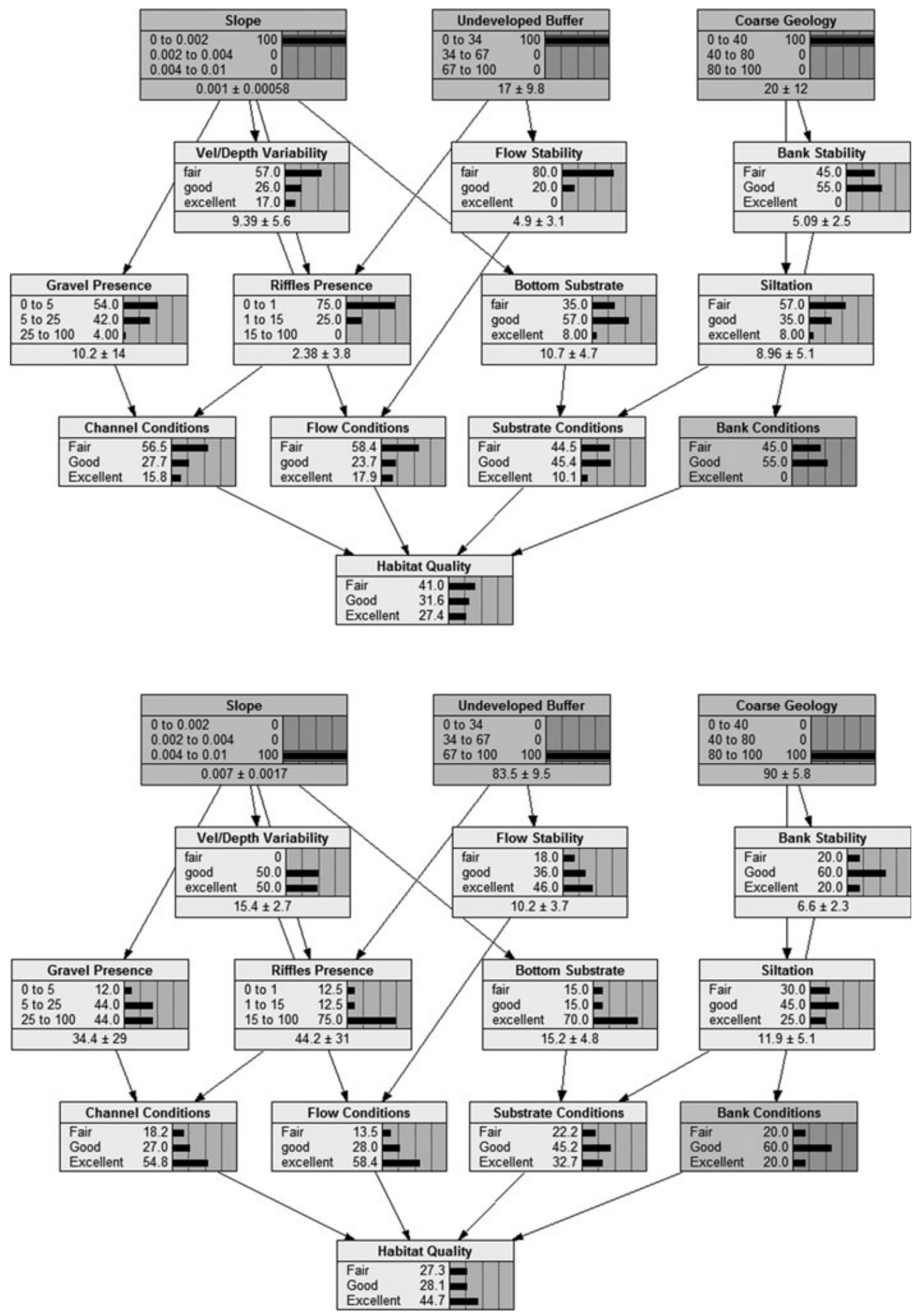

Fig. 7 The southeastern Michigan habitat model run for scenarios expected to result in poor habitat (top) and best habitat (bottom). Overall habitat quality is twice as likely to be excellent if slope, buffer land use, and catchment geology all fall in the highest or best categories. 
Table 1 The model for the Raisin-Huron catchments was run for each of 47 sites, which were then grouped according to their probability of having 'excellent' habitat. An independent analysis (Infante et al., 2008) identified seven of the 47 sites as having the most ecologically and functionally diverse fish group. Sites predicted to be most likely to have excellent habitat were also more likely to have the most diverse fish assemblage

\begin{tabular}{lll}
\hline $\begin{array}{l}\text { Predicted frequency } \\
\text { of excellent habitat (\%) }\end{array}$ & $\begin{array}{l}\text { Number } \\
\text { of sites }\end{array}$ & $\begin{array}{l}\text { Member of most } \\
\text { diverse fish group }\end{array}$ \\
\hline $21-23$ (lowest) & 13 & 0 \\
$22-29$ & 10 & 1 \\
$30-34$ & 13 & 2 \\
$35-45$ (highest) & 11 & 4 \\
\hline
\end{tabular}

ative correlations between the proportion of the catchment area above the sample site used for grazing and EPT, $\mathrm{O} / \mathrm{E}$, and Bray-Curtis similarity to reference sites. Analysis of data by hydrological region, as well as partial redundancy analysis accounting for the effects of geographical and local environmental factors, confirmed the generality of this relationship between grazing land-use and river macroinvertebrate community responses. Regression-tree analysis indicated that catchments with over $40 \%$ of land under grazing experienced declines in $\%$ EPT and O/E of 30-50\% (N. Horrigan, P.E. Davies, S.M. Read \& R.H. Magierowski, in review). Analysis at two different scales indicated that catchment-scale land use and riparian condition were (especially for grazing) stronger determinants of macroinvertebrate community structure and site-scale habitat responses than was localscale land use within the immediately proximal catchment (within ca 2-km stream length upstream). This indicated that catchment-wide rather than local land and riparian vegetation management actions would be required to mitigate the impact of certain land uses on Tasmanian river health, and that both catchment-scale and local reach-scale factors must be nested within the BBN structure. This reinforces the concept that scale must be an explicit consideration in modelling the link between land use and stream responses (Townsend et al., 2004).

The gradient field surveys were designed to detect relationships between stream ecology and the extent and history of grazing and forestry within upstream catchments. Benthic macroinvertebrates and algae were sampled, and a range of site and reach habitat characteristics were recorded in the most downstream reach of 27 catchments that covered a range from 0 to $60 \%$ of area under grazing land use, with forestry and conservation (minimal use) as the remaining land uses. An additional 41 catchments were sampled to cover a range of areas and age structures of forestry management within three classes - intensive forestry (typified by clearfelling, burning and sowing operations), low-intensity forestry (typified by thinning and selective harvesting) and plantations (dominated by Eucalyptus nitens monoculture). In both cases, local GIS data were used to identify the land use and forest management histories of the catchments and to assist with site selection. Care was taken to remove catchments influenced by other disturbances (mining, impoundment etc.) and by unusual geomorphology (e.g. granitic geology). A range of other spatial data were derived from the CFEV (DPIW, 2008) data layers and used to develop local correlations between key variables as an aid in determining CPT values. For example, data on net abstraction from streamflow were correlated with area under grazing to derive links between land use and the intensity of hydrological change.

Local evidence was also required for several key processes: riparian shading control of light and benthic algal production, trophic dependence of macroinvertebrates on algal or terrestrial carbon sources and control and limitation of benthic algal growth rates by nutrient concentrations and light levels. Methods used to obtain these data in the Tasmanian study catchments included deployment of benthic chambers and open channel oxygen measurements to estimate respiration and production at sites across a range of riparian shading intensity (Bott, 2006; Grace \& Imberger, 2006); determination of stable carbon and nitrogen isotope ratios for food sources, grazers and predators at sites across the field gradients (Hershey et al., 2006); and deployment of nutrient-diffusing substrata at stream sites selected across a range of ambient nutrient loads to assess growth rates and nutrient and shading limitation of benthic algae (Pringle \& Triska, 2006).

All the aforesaid evidence is correlative and did not allow differentiation between the co-varying influences of changes in nutrient concentrations, fine sediment impacts and changed light levels as land-use intensity increased across the catchments. To address this problem, two stream mesocosm experiments were used to discriminate biological responses to nutrients and fine sediment deposition under high and low levels of shading. Eight sets of four replicate 5-m channels were colonised for 3 months with continuous flow from the forested Little Denison River watershed (a forested catchment with similar size, climate, topography vegetation and stream biota to the gradient survey catchments). The sets of streams were allocated in a stratified random manner to one of a high or low nutrient and high or low sediment treatment in a fully factorial design. Treatments continued for 3 months, after which a range of measures of macroinvertebrate and algal community composition as well as benthic metabolism 
J. David Allan et al.

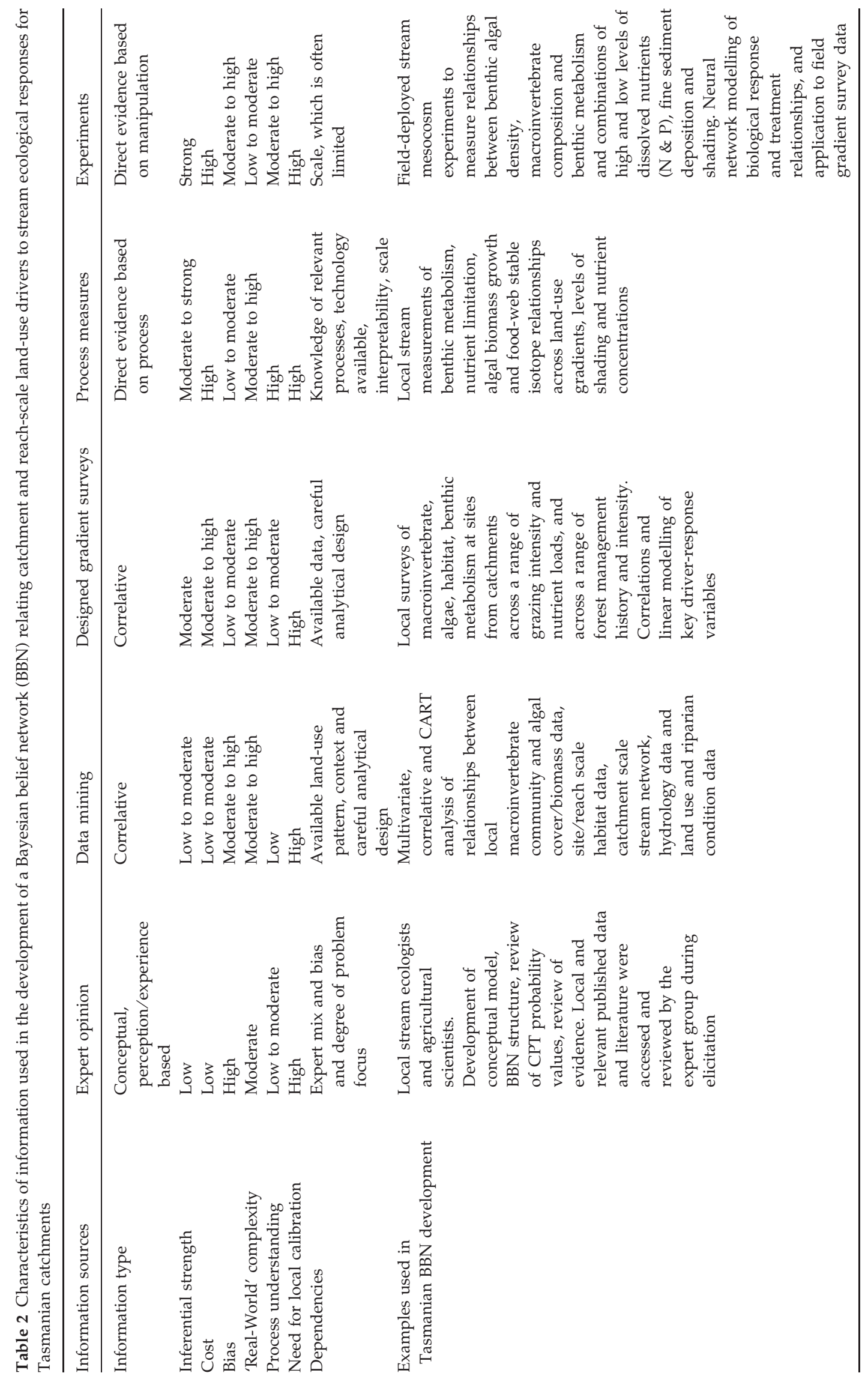


Fig. 8 Conceptual model of Tasmanian river responses to catchment-scale land use and related drivers. Scale of each node is shown, and strength of link is indicated by arrow widths. Level of evidentiary support is indicated by ticks.

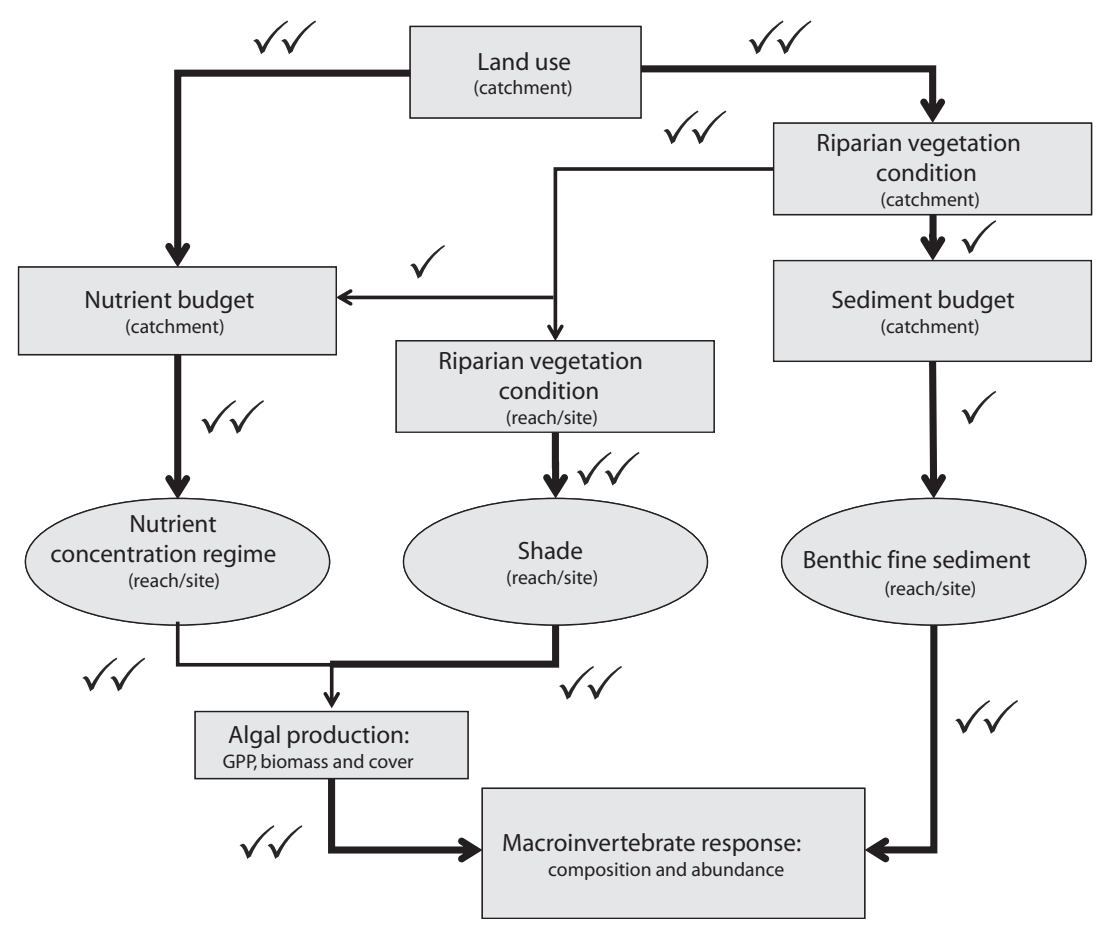

used to determine the strength of the relevant parentdaughter state relationships in the BBN.

Data-derived relationships (correlations from data mining and survey data sets) between the biological variables, proximal variables and distal land use and catchment condition variables, represented in the BBN by nodes (Fig. 9), were used to derive initial CPT values. Where these were deemed inadequate (data range limited, missing cases), the CPT values were supplemented by elicitation in structured workshops with experts relevant to specific node sets. The results of the artificial stream network were then used to refine several CPT values in order to discriminate the influence of changed nutrient and fine sediment deposition on the biological nodes.

The final output nodes for the BBN (Fig. 9) were designed to be of direct relevance to regional natural resource management (NRM) in Tasmania as part of the Australian Landscape Logic initiative (http:/ / www.lands capelogic.org.au). These output nodes calculate scores for indices of condition of macroinvertebrate assemblages and benthic algae, as well as an overall Aquatic Life Condition Index score. These indices, established under the Tasmanian River Condition Index protocol (NRM South, 2009), are used for river condition reporting and target setting by the state government and the Tasmanian NRM regional management bodies.

Evaluation of the model using both internal and independent data sets (by jack-knife and correlation, respectively) indicated reasonable correspondence of 


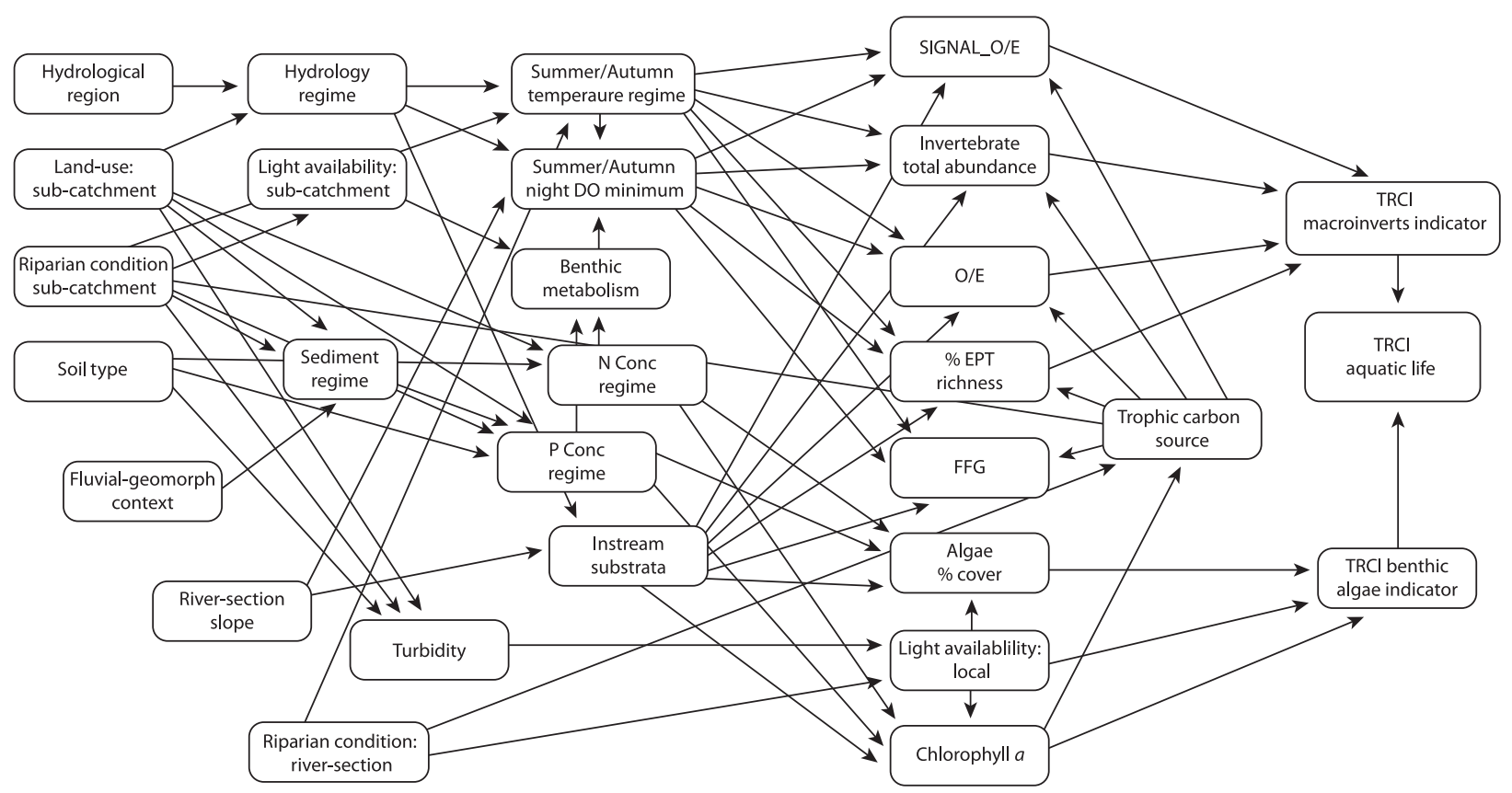

Fig. 9 Architecture of Tasmanian river Bayesian belief network showing input nodes on left, intermediate responses and site-scale benthic responses in middle of graph, and output indicators on right. Measures of the invertebrate community condition include O/E (families observed/expected), \%EPT (per cent Ephemeroptera, Plecoptera and Trichoptera) and FFG (functional feeding groups). TRCI refers to the Tasmanian River Condition Index.

observed and predicted condition, although declines in $\%$ EPT under high-intensity forestry are greater at some sites than the model predicts (e.g. Fig. 10). Further testing is planned. In the future, this model can be used to investigate the influence of varying combinations of driver states on these aquatic biological indices. Diagnostic application also is possible by fixing output node state values and examining driver state probability distributions. Within set contexts (of dominant soil type, stream

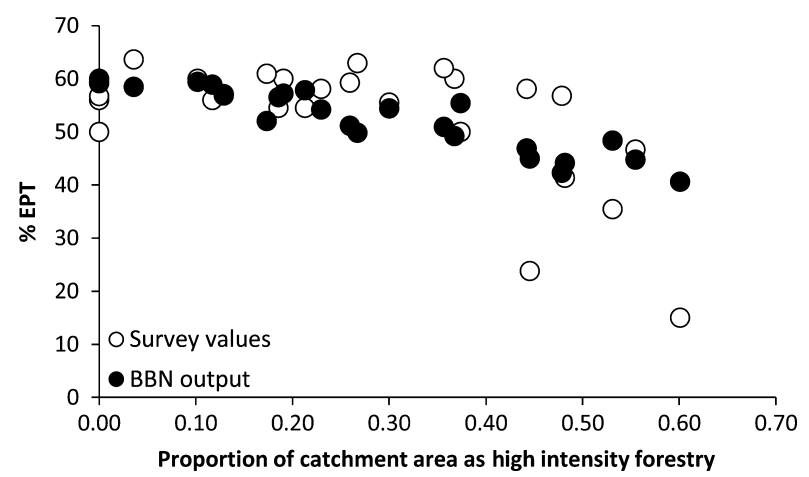

Fig. 10 Relationship between the percentage of benthic macroin vertebrate taxa from the aquatic insect orders Ephemeroptera, Plecoptera and Trichoptera (\%EPT) and the proportion of area under high-intensity forestry land use, for 26 Tasmanian catchments. Values shown are from field survey (clear circles) and as outputs of the Bayesian belief network (filled circles). Remaining land use in all catchments is reservation and $<10 \%$ low intensity forestry. reach slope, hydrological region, dominant land uses, etc.), biological evidence can be entered into the BBN and the probability of different states of selected drivers (such as riparian condition, relative nutrient load, water use) can be examined. The efficacy of a variety of different management options in achieving specific target score values or ranges can also be explored.

\section{Discussion}

An advantage of BBNs is their ability to exploit diverse sources of information to explicitly represent probabilistic relationships in a conceptually formulated causal chain. The discipline of explicitly articulating a conceptual model forces modellers and stakeholders to formally evaluate and express beliefs concerning causal mechanisms and facilitates model revision during development (Burgman, 2005). The three cases illustrate alternative approaches to the development of a BBN and the flexibility this accords. With such a model, the effects of different management options for stream systems can be evaluated, and future conditions could be predicted based on forecasts of land-use change or implementation of best management practices. Running the model in the reverse direction would facilitate diagnosis of the likely causes of impairment to a stream given a set of biological characteristics. 
The three case studies focus primarily on model development; none was fully tested against independent data. The elicitation model is broadly consistent with a recent analysis of large data sets for clingers and sediments (Pollard \& Yuan, 2010), and the southeastern Michigan case shows at least internal consistency. The Tasmanian model has undergone preliminary testing (Fig. 10) and initial results are encouraging. This model will be extensively used in management decision-making in the near future, which should provide further insight into its utility.

The objective of the case study for characterising the relationship between sedimentation and population density of macroinvertebrates was to demonstrate the feasibility of using expert elicitation to build a BBN of a stream ecosystem sub-model. To our knowledge, no empirical data exist that would quantify the relationship depicted in Fig. 4 for clingers, nor for the other functional groups considered. Indeed, the mismatch we observed between the variables that experts needed to express mechanistic relationships (e.g. clinger density and per cent embeddedness) and the variables that were readily available from field observations (e.g. clinger relative abundance and per cent substratum sand/fines) may be informative for subsequent research towards defining mechanistic relationships in stream ecosystems. Furthermore, expert judgment within a formalised modelling structure led to a better understanding of causal relationships between environmental stressors and population responses, and a model outcome that participants believed was a reasonable representation of the expected relationship. The exercise of building such a model forced the team to define the scope of the problem more precisely than otherwise might be the case. Elicitation may be criticised because of the difficulty of testing or evaluating the models, but it can be the only reasonable option for model development when appropriate data are difficult to obtain, and it can provide useful insights into the most pressing needs for future research and data collection. Participants in the sedimentation elicitation case were in agreement that the elicited model reflected their consensus view of a stressor-response relationship considered to be of wide significance in stream impairment.

The southeastern Michigan case developed directly from field survey data was in essence an effort to explore the ability of a limited number of prior variables to predict stream condition, represented directly by habitat quality and secondarily by species and functional diversity of the fish assemblage. Both habitat quality and fish diversity were predicted moderately well; however, the model was not tested directly with an independent data set. Because of its reliance on data from a specific region, it presumably has the limited generality of a statistical analysis of the same data; comparison with other data sets would be the most reasonable test of the extent of its applicability elsewhere. Attempts to use the Michigan model in reverse', to infer causal conditions, were disappointing. It seems likely that the relatively weak statistical associations used to develop the CPTs (e.g. Fig. 6) resulted in a causal chain of low predictive strength, making it difficult to work backwards from effect to probable cause. In their model of eutrophication in the Neuse River estuary, North Carolina, Borsuk et al. (2004) concluded that the further down the causal chain a variable was, the greater the predictive uncertainty.

The Tasmanian mixed model is the most detailed and information-rich and likely holds the greatest promise for rapid management utility and uptake. Two applications have been developed from this BBN (see http:// www.landscapelogicproducts.org.au). Outcomes from sets of scenarios have been documented in 'fact sheets' to inform managers in making investment decisions for catchment and riparian management. These relate stream health to a variety of combinations of land use, riparian condition, and related 'drivers' in graphical and text form. In addition, the BBN has been incorporated into a multiBBN decision support system for Tasmanian catchment and natural resource managers to apply scenarios at whole of catchment scales. Training has already been conducted in its use in the three Tasmanian management regions.

Presumably any of the models could be adapted to a different setting, but probabilistic relationships likely are specific to a rather narrow set of conditions, and the variables and probabilistic relationships may need to be re-considered as the problem setting diverges from the original conception. Assuming that the goals are to depict causal relationships and to help specific management activities, each BBN is expected to be rather narrow in its scope. The approach itself is flexible, however, as we have attempted to illustrate with diverse examples.

\section{Acknowledgments}

The expert elicitation workshop was sponsored by the Office of Research and Development, National Center for Environmental Assessment, USEPA. Research on the southeastern Michigan watersheds was supported by a grant from the Water and Watersheds Program of EPA and NSF. Tasmanian studies were supported by the Landscape Logic Research Hub, with funding from the Australian Commonwealth Environmental Research 
Facilities scheme (Department of Environment, Water, Heritage and the Arts). We thank W. Dodds, L. Johnson, M. Palmer, B. Wallace and EPA staff for participation in the expert elicitation process. We thank reviewers of the manuscript and David Strayer for helpful comments.

\section{References}

Allan J.D. (2004) Landscape and riverscapes: the influence of land use on river ecosystems. Annual Reviews of Ecology, Evolution and Systematics, 35, 257-284.

Allan J.D. \& Castillo M.M. (2007) Stream Ecology. Springer, Dordrecht, The Netherlands.

ANDRL (2008) Australian Natural Resources Data Library. Accessed online 24 March 2009 at: http://adl.brs.gov.au.

Barbour M.T., Gerritsen J., Snyder B.D. \& Stribling J.B. (1999) Rapid Bioassessment Protocols for Use in Streams and Wadeable Rivers: Periphyton, Benthic Macroinvertebrates and Fish, 2nd edn. EPA 841-B-99-002. U.S. Environmental Protection Agency, Office of Water, Washington, D.C.

Borsuk M.E., Stow C.A. \& Reckhow K.H. (2004) A Bayesian network of eutrophication models for synthesis, prediction, and uncertainty analysis. Ecological Modelling, 173, 219-239.

Bott T.L. (2006) Primary productivity and community respiration. In: Methods in Stream Ecology (Eds F.H. Hauer \& G.A. Lamberti ), pp. 663-690. Academic Press, Burlington.

Burgman M.A. (2005) Risks and Decisions for Conservation and Environmental Management. Cambridge University Press, New York.

Davies P.E. (2000). Development of a national river bioassessment system (AUSRIVAS) in Australia. In: Assessing the Biological Quality of Freshwaters: RIVPACS and Other Techniques. (Eds J.F. Wright, D.W. Sutcliffe \& M.T. Furse ), pp. 113-124. Freshwater Biological Association, Cumbria, UK.

Davies P.E. \& Nelson M. (1994) Relationships between riparian buffer widths and the effects of logging on stream habitat, invertebrate community composition and fish abundance. Australian Journal of Marine and Freshwater Research, 45, 1289-1305.

Davies P.E., Cook L.S.J., McIntosh P. \& Munks S.A. (2005a) Changes in stream biota along a gradient of logging disturbance, 15 years after logging at Ben Nevis, Tasmania. Forest Ecology and Management, 219, 132-148.

Davies P.E., McIntosh P., Wapstra M., Bunce S., Cook L.S.J., French B. et al. (2005b) Changes to headwater stream morphology, habitats and riparian vegetation recorded 15 years after pre-Forest Practices Code forest clearfelling in upland granite terrain, Tasmania, Australia. Forest Ecology and Management 217, 331-350.

Davies P.E., Harris J.H., Hillman T.J. \& Walker K.F. (2010) The sustainable rivers audit: assessing river ecosystem health in the Murray Darling Basin, Australia. Marine and Freshwater Research, 61, 764-777.
Diana M.J., Allan J.D. \& Infante D.M. (2006) The influence of habitat and land use on fish assemblages of streams in southeastern Michigan. In: Influences of Landscape on Stream Habitats and Biological Assemblages (Eds R.M. Hughes, L. Wang \& P.W. Seelbach ), pp. 359-374. American Fisheries Society, Symposium 48, Bethesda, MD.

Downes B.J. (2010) Back to the future: little-used tools and principles of scientific inference can help disentangle effects of multiple stressors on freshwater ecosystems. Freshwater Biology 55(Suppl. 1), 60-79.

DPIW (2008) Conservation of Freshwater Ecosystem Values (CFEV) Project Technical Report. Conservation of Freshwater Ecosystem Values Program. Department of Primary Industries and Water, Hobart, Tasmania, $227 \mathrm{pp}$.

Farrand W.R. \& Bell D.L. (1982) Quaternary Geology of Southern Michigan (map). Department of Geological Sciences, University of Michigan, Ann Arbor, MI.

Grace M.R. \& Imberger S.J. (2006) Stream metabolism: performing \& interpreting measurements. Water Studies Centre, Monash University, Murray Darling Basin Commission and New South Wales Department of Environment and Climate Change. 204 pp. Accessed online 1 April 2009 at: http://www.sci.monash.edu.au/wsc/ docs/tech-manual-v3.pdf.

Haas T.C., Mowrer H.T. \& Shepperd W.D. (1994) Modeling aspen stand growth with a temporal Bayes network. Artificial Intelligence Applications, 8, 15-28.

Hershey A.E., Fortino K., Peterson B.J. \& Ulseth A.J. (2006) Stream food webs. In: Methods in Stream Ecology (Eds F.H. Hauer \& G.A. Lamberti ), pp. 637-661. Academic Press, Burlington.

Hughes J.M.R. (1987) Hydrological characteristics and classification of Tasmanian rivers. Australian Geographical Studies, 25, 61-82.

Hughes R.M., Wang L. \& Seelbach P.W. (Eds) (2006) Influences of Landscape on Stream Habitats and Biological Assemblages. American Fisheries Society, Symposium 48, Bethesda, Maryland.

Infante D.M. \& Allan J.D. (2010) Response of stream fish assemblages to local-scale habitat as influenced by landscape: a mechanistic investigation of stream fish assemblages. In: Community Ecology of Stream Fishes (Eds K.B. Gido \& D.A. Jackson ), pp. 371-400. American Fisheries Society, Symposium 73, Bethesda, Maryland.

Infante D.M., Allan J.D., Linke S. \& Norris R.H. (2008) Relationship of fish and macroinvertebrate assemblages to environmental factors: implications for community concordance. Hydrobiologia, 623, 87-103.

Jensen F.V. (1996). An Introduction to Bayesian Networks. UCL Press, London.

Jerie K., Houshold I. \& Peters D. (2001) Stream diversity and conservation in Tasmania: yet another new approach. In: Proceedings of the 3rd Australian Stream Management Conference, CRC for Catchment Hydrology, Melbourne, Australia pp. 329-335. 
Jerie K., Houshold I. \& Peters D. (2003) Tasmania's River Geomorphology: Stream Character and Regional Analysis, Vol. 1. Nature Conservation Report 03/5. Nature Conservation Branch, DPIWE, Hobart, Tasmania, 66 pp.

Johnson L.B., Host G.E. (2010) Recent developments in landscape approaches for the study of aquatic ecosystems. Journal of the North American Benthological Society, 29, 41-66.

Korb K.B. \& Nicholson A.E. (2004) Bayesian Artificial Intelligence. Chapman and Hall/CRC Press, London, 364 pp.

Kuikka S., Hilden M., Gislason H., Hansson S., Sparholt H. \& Varis O. (1999) Modeling environmentally driven uncertainties in Baltic cod (Gadus morhua) management by Bayesian influence diagrams. Canadian Journal of Fisheries and Aquatic Sciences, 56, 629-641.

Lammert M. \& Allan J.D. (1999) Assessing biotic integrity of streams: effects of scale in measuring the influence of land use/cover and habitat structure on fish and macroinvertebrates. Environmental Management 23, 257-270.

Lee D.C. \& Rieman B.E. (1997) Population viability assessment of salmonids using probabilistic networks. North American Journal of Fisheries Management, 17, 11441157.

Michigan Department of Environmental Quality (MDEQ). (1997) Qualitative biological and habitat survey protocols for wadeable streams and rivers. MI/DEQ/SWQ-96/068.

NRM South (2009) Tasmanian River Condition Index Reference Manual. NRM South, Hobart, Australia, 250 pp. Accessed online 1 July 2009 at: http://www.nrmsouth.org.au/ uploaded/287/15130402_19trcireferencemanualweb.pdf

Paulsen S.G., Mayio A., Peck D.V., Stoddard J.L., Tarquino E. \& Holdsworth S.M. et al. (2008) Condition of stream ecosystems in the US: an overview of the first national assessment. Journal of the North American Benthological Society, 27, 812-821.

Plowright R.K., Sokolow S.H., Gorman M.E., Daszak P. \& Foley J.E. (2008) Causal inference in disease ecology: investigating ecological drivers of disease emergence. Frontiers in Ecology and the Environment, 6, 420-429.

Pollard A.I. \& Yuan L.L. (2010) Assessing the consistency of response metrics of the invertebrate benthos: a comparison of trait- and identify-based measures. Freshwater Biology 55, 1420-1429.

Pollino C.A., Woodberry O., Nicholson A., Korb K. \& Hart B.T. (2007) Parameterisation and evaluation of a Bayesian
Bayesian belief networks for stream condition

73

network for use in an ecological risk assessment. Environmental Modelling and Software 22, 1140-1152.

Pringle C.M. \& Triska F.J. (2006) Effects of nutrient enrichment on periphyton. In: Methods in Stream Ecology (Eds F.H. Hauer \& G.A. Lamberti ), pp. 743-760. Academic Press, Burlington.

Rieman B.E., Peterson J.T., Clayton J., Howell P., Thurow R., Thompson W. et al. (2001) Evaluation of potential effects of federal land management alternatives on trends of salmonids and their habitats in the interior Columbia River basin. Forest Ecology and Management, 153, 43-62.

Roth N.E., Allan J.D. \& Erickson D.L. (1996) Landscape influences on stream biotic integrity assessed at multiple spatial scales. Landscape Ecology, 11, 141-156.

Smith B.J., Davies P.E. \& Munks S.A. (2009) Changes in benthic macroinvertebrate communities in upper catchment streams in Tasmania across a gradient of catchment forest operation history. Forest Ecology and Management, 257, 2166-2174.

Steel E.A., Hughes R.M., Fullerton A.H. et al. (2010) Are we meeting the challenges of landscape-scale riverine research? A review. Living Reviews in Landscape Research 4, 1. Available at: http://www.livingreviews.org/lrlr2010-1 (accessed on 14 July 2010).

Stewart-Koster B., Bunn S.E., Mackay S.J., Poff N.L., Naiman R.J. \& Lake P.S. (2005) The use of Bayesian networks to guide investments in flow and catchment restoration for impaired river ecosystems. Freshwater Biology, 55, 243-260.

Townsend C.R., Downes B.J., Peacock K. \& Arbuckle C.J. (2004) Scale and the detection of land-use effects on morphology, vegetation and macroinvertebrate communities of grassland streams. Freshwater Biology, 49, 448-462.

US Environmental Protection Agency (EPA) (2000) The Quality of our Nation's Waters: a Summary of the National Water Quality Inventory 1998 Report to Congress. EPA 841-S00-001. Office of Water, Washington, DC.

Webb J.A., Stewardson M.J. \& Koster W.M. (2010) Detecting ecological responses to flow variation using Bayesian hierarchical models. Freshwater Biology, 55, 108-126.

Yuan L.L. (2004) Assigning macroinvertebrate tolerance classifications using generalized additive models. Freshwater Biology, 49, 662-677.

(Manuscript accepted 1 August 2011) 